\title{
Risk of Diabetes in Patients with Long-Standing Graves' Disease: A Longitudinal Study
}

\author{
Eyun Song ${ }^{1}$, Min Ji Koo ${ }^{2}$, Eunjin Noh², Soon Young Hwang ${ }^{3}$, Min Jeong Park ${ }^{1}$, Jung A Kim ${ }^{1}$, Eun Roh ${ }^{1}$, \\ Kyung Mook Choi ${ }^{1}$, Sei Hyun Baik ${ }^{1}$, Geum Joon Cho ${ }^{4}$, Hye Jin Yoo ${ }^{1}$ \\ ${ }^{1}$ Division of Endocrinology and Metabolism, Department of Internal Medicine, Korea University College of Medicine; ${ }^{2}$ Smart \\ Healthcare Center, Korea University Guro Hospital, Korea University College of Medicine; Departments of ${ }^{3}$ Biostatistics, \\ ${ }^{4}$ Obstetrics and Gynecology, Korea University College of Medicine, Seoul, Korea
}

Background: The detrimental effects of excessive thyroid hormone on glucose metabolism have been widely investigated. However, the risk of diabetes in patients with long-standing hyperthyroidism, especially according to treatment modality, remains uncertain, with few longitudinal studies.

Methods: The risk of diabetes in patients with Graves' disease treated with antithyroid drugs (ATDs) for longer than the conventional duration ( $\geq 2$ years) was compared with that in age-and sex-matched controls. The risk was further compared according to subsequent treatment modalities after a 24-month course of ATD: continuation of ATD (ATD group) vs. radioactive iodine ablation (RIA) group. Results: A total of 4,593 patients were included. Diabetes was diagnosed in 751 (16.3\%) patients over a follow-up of 7.3 years. The hazard ratio (HR) for diabetes, after adjusting for various known risk factors, was 1.18 (95\% confidence interval [CI], 1.10 to 1.28 ) in patients with hyperthyroidism. Among the treatment modality groups, the RIA group $(n=102)$ had a higher risk of diabetes than the ATD group $(n=4,491)$ with HR of $1.56(95 \%$ CI, 1.01 to 2.42). Further, the risk of diabetes increased with an increase in the ATD treatment duration $(P$ for trend $=0.019)$.

Conclusion: The risk of diabetes was significantly higher in patients with long-standing Graves' disease than in the general population, especially in patients who underwent RIA and prolonged ATD treatment. Special attention to hyperglycemia during follow-up along with effective control of hyperthyroidism may be necessary to reduce the risk of diabetes in these patients.

Keywords: Hyperthyroidism; Graves disease; Diabetes mellitus; Antithyroid agents; Radioiodine ablation

\section{INTRODUCTION}

Hyperthyroidism is a pathological condition characterized by excessive synthesis and secretion of thyroid hormones [1]. The most common cause of hyperthyroidism is Graves' disease, which is an autoimmune disease caused by autoantibodies tar-

Received: 8 September 2021, Revised: 22 October 2021,

Accepted: 4 November 2021

Corresponding author: Hye Jin Yoo

Division of Endocrinology and Metabolism, Department of Internal Medicine, Korea University College of Medicine, 148 Gurodong-ro, Guro-gu, Seoul 08308 , Korea

Tel: +82-2-2626-3045, Fax: +82-2-2626-1096, E-mail: deisy21@naver.com geting thyrotropin receptors [2]. Antithyroid drugs (ATDs) are currently used as the primary treatment for most patients with Graves' disease [3,4]. Despite following the recommended 12 to 18 months of treatment, the remission rate with ATD use remains as low as $30 \%$ to $40 \%$, and the recurrence rate is as high as $54 \%$ [5]. A considerable number of patients with Graves' dis-

\section{Copyright $(\odot 2021$ Korean Endocrine Society}

This is an Open Access article distributed under the terms of the Creative Commons Attribution Non-Commercial License (https://creativecommons.org/ licenses/by-nc/4.0/) which permits unrestricted non-commercial use, distribution, and reproduction in any medium, provided the original work is properly cited. 
ease require ATD therapy beyond the recommended treatment period $[6,7]$ and are thus subjected to an elevated risk of various metabolic disturbances caused by excessive thyroid hormone production.

The effects of thyroid hormones on glucose metabolism are well recognized [8]. Thyroid dysfunction and diabetes mellitus (DM) can often coexist in patients, with the prevalence of thyroid dysfunction in diabetic patients ranging from $10.8 \%$ to $13.4 \%$ [9-11]. The association between these two conditions lies in the complex interplay of biochemical, genetic, and hormonal malfunctions [12-14], wherein thyroid hormones have a direct and indirect role in regulating insulin secretion, hepatic glucose output, and glucose disposal in peripheral tissues [8,15]. Previous studies have examined the association between thyroid dysfunction and DM; however, most were cross-sectional studies and lacked temporal relationships [9,16-21]. Moreover, these studies, albeit controversial, primarily focused on the risk of thyroid disease in patients with diabetes.

In contrast, the development of new-onset DM in patients with thyroid dysfunction lacks sufficient data, especially in relation to hyperthyroidism and its treatment modalities. Considering the detrimental effect of elevated thyroid hormones on glucose homeostasis and the protracted exposure to this condition in patients undergoing long-term ATD therapy for Graves' disease, our study aimed to assess the risk of DM in patients recently diagnosed with Graves' disease who received ATDs for longer than the conventional duration ( $\geq 2$ years). We also aimed to evaluate and compare the risk of DM on the basis of different treatment modalities after the conventional course of ATDs: continuing ATD or performing radioactive iodine ablation (RIA).

\section{METHODS}

\section{Data source}

This retrospective cohort study used data from the Korean $\mathrm{Na}$ tional Health Insurance Service (NHIS) database run by the Korean government [22]. Covering up to $98 \%$ of the entire national population, the NHIS contains information on anonymized personal data, health examination details, demographics, diagnoses based on International Classification of Diseases Tenth Revision (ICD-10) codes, inpatient and outpatient claims data, and medical treatments. In addition, all participants enrolled in the NHIS are recommended to undergo general health examinations at least biannually. The results of general health examinations and questionnaires on lifestyle and behavior from this screening are registered in the National Health Screening Database. The study protocol was approved by the Institutional Review Board of Korea University (IRB file number 2020GR0206). A waiver for the requirement of informed consent was granted by the IRB as the data provided by the Korean NHIS to the researchers was de-identified and only used anonymous identification numbers.

\section{Study design and population}

Subjects diagnosed with hyperthyroidism (ICD-10 codes: E05.0, E05.8, and E05.9) between 2005 and 2012, who began ATD treatment within 90 days of diagnosis were initially screened (Fig. 1). To select patients with newly diagnosed hyperthyroidism, a 3-year washout period from 2002 to 2004 was applied. As a 12 to 18 -month period is regarded as the upper limit for ATD treatment duration for managing Graves' disease, and administration of ATD over 18 to 24 months may not be beneficial according to the current guidelines [5,6,23], patients treated with ATD for $\geq 24$ months after the diagnosis of hyperthyroidism were defined as having long-standing Graves' disease. Among the patients with long-standing Graves' disease, those who underwent at least one National Health Screening Examination between 2010 and 2012 (index year) and were on active treatment for Graves' disease (ATD or RIA) during this period were ultimately selected for our study. Subjects aged $<18$ years, who had already been diagnosed with DM (ICD-10 codes: E10-E14), had a history of thyroid cancer (ICD-10 code: C73), or died before the index year, were excluded. Controls were selected from among subjects without hyperthyroidism, DM, or thyroid cancer and who had undergone at least one National Health Screening Examination between 2010 and 2012. These were 1:10 matched to the case subjects per age and sex.

\section{Subgrouping}

Patients were classified into two groups according to subsequent treatment modalities following the initial 24-month ATD course: patients who continued ATD for at least 12 more months without RIA treatment (ATD group) and those who underwent RIA at any point after the initial ATD course (RIA group). Furthermore, to assess the risk of DM on the basis of ATD treatment duration, patients were categorized as follows: ATD treatment for 2 to 3 years, 3 to 4 years, and $\geq 4$ years. The duration of ATD treatment was calculated as the sum of the total administration period of ATD from the initial prescription of ATD to the discontinuation of ATD for patients in the ATD group, regardless of the ATD type (propylthiouracil, methimazole, or carbimazole). For patients in the RIA group, the duration of ATD treatment was calculated as the sum of the total adminis- 


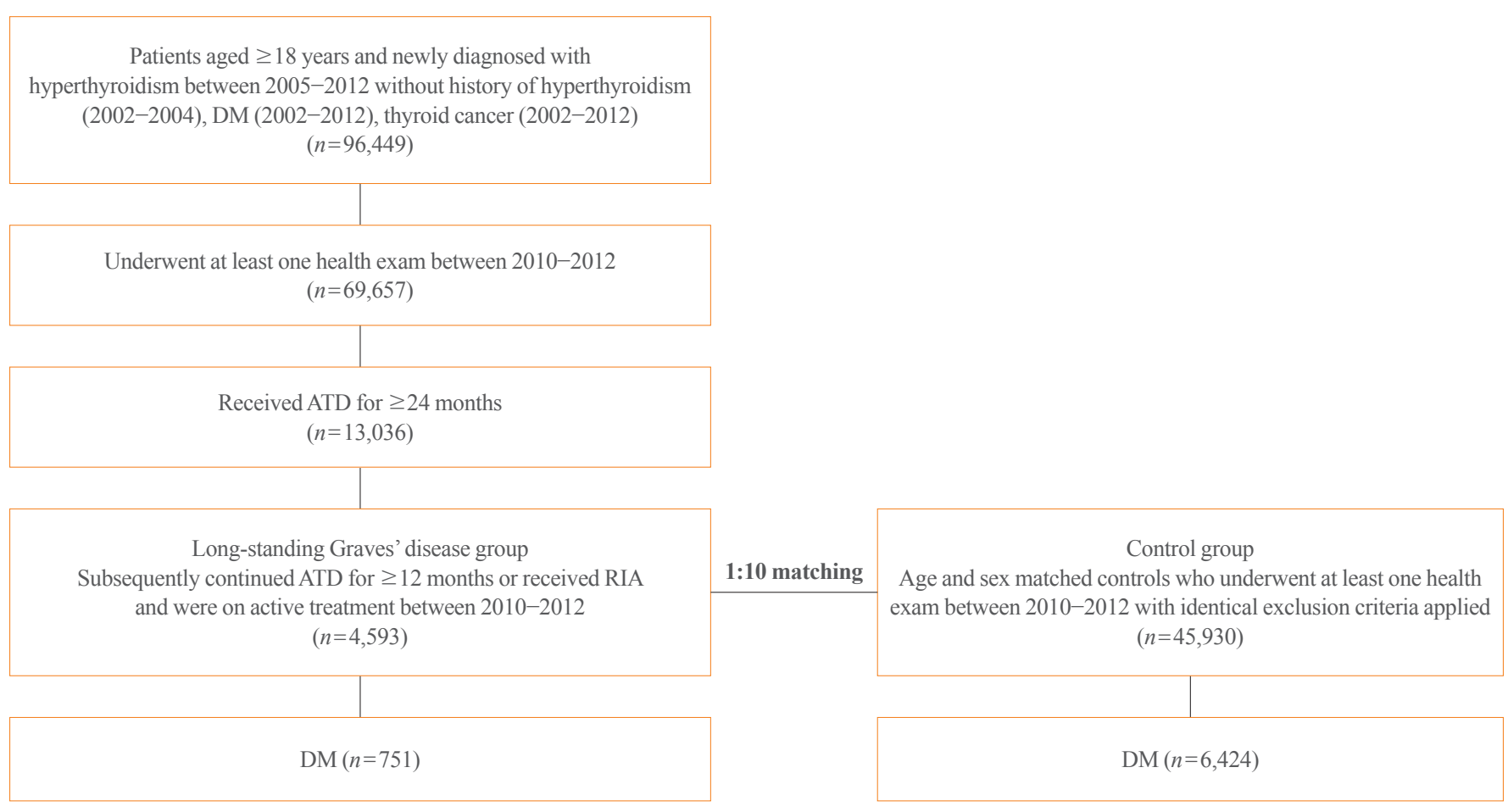

Fig. 1. Flowchart of the study. DM, diabetes mellitus; ATD, antithyroid drug; RIA, radioactive iodine ablation.

tration period of ATD from the initiation of ATD therapy to the date of ablation.

\section{Primary outcome and follow-up}

The primary outcome was new-onset DM, which was determined by recording the ICD-10 code for DM (codes E10-E14) or determining the fasting blood glucose (FBG) to be $\geq 126 \mathrm{mg} /$ dL. Follow-up was continued until development of the outcome, death, or December 2019, whichever was earlier.

\section{Covariates}

Data on baseline characteristics including body mass index (BMI), blood pressure (BP), cholesterol levels, FBG, smoking status (never, past, or current), alcohol consumption, and exercise status were obtained for both case subjects and controls from the National Health Screening Examination performed between 2010 and 2012. Heavy alcohol consumption was defined as an average daily alcohol intake of $\geq 30 \mathrm{~g}$, and regular exercise was defined as moderate to strenuous physical activity $\geq 3$ times/week. The latest data were used if subjects had undergone health screening examinations more than once during this period. Comorbidities were defined as the presence of recording a minimum of two ICD-10 codes for each diagnosis within 2 years before the latest health screening examination: codes I10-
13 or I15 for hypertension and E78 for dyslipidemia.

\section{Statistical analysis}

Data were analyzed using the SAS software version 9.4 (SAS Institute Inc., Cary, NC, USA). Continuous variables are presented as medians with interquartile ranges or means with standard deviations, analyzed using the Mann-Whitney $U$ test or Student's $t$ test, respectively. Categorical variables are presented as counts with percentages and were compared using Pearson's chi-square test. The Kaplan-Meier method was used to construct the curves for cumulative incidence of DM, and the logrank test was used to compare the incidence between the groups. The hazard ratio (HR) and 95\% confidence interval (CI) for DM were calculated using the Cox proportional hazard model by adjusting for various confounding factors using the following steps: Model 1 adjusted for age and sex; Model 2 adjusted for age, sex, BMI, smoking status, alcohol consumption, regular exercise, comorbidities (hypertension and dyslipidemia); and Model 3 additionally adjusted for systolic BP, low-density lipoprotein, and FBG. In addition, subgroup analyses were performed to evaluate the potential effect modification by age, sex, BMI, smoking status, alcohol consumption, and presence of comorbidities (hypertension and dyslipidemia), and $P$ values for interactions were calculated. 

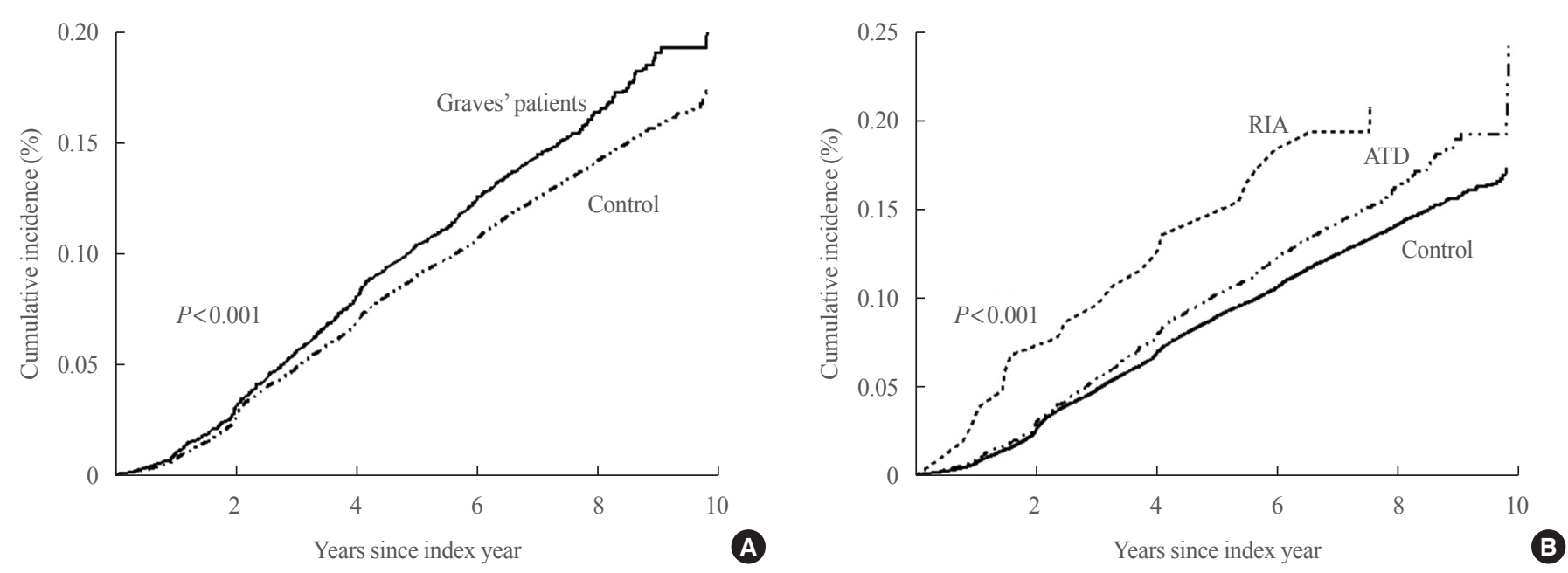

Fig. 2. Kaplan-Meier curves for cumulative incidence of new-onset diabetes (A) in total long-standing Graves' patients and (B) among the treatment modality groups compared to the controls. ATD, antithyroid drug; RIA, radioactive iodine ablation.

\section{RESULTS}

\section{Baseline characteristics}

A total of 4,593 patients with long-standing Graves' disease and 45,930 controls were included in the study (Fig. 1). The baseline characteristics are summarized in Table 1 . The median age was 48 years, and women accounted for $65 \%$ of the patients in each group. FBG was lower at baseline in subjects in the hyperthyroidism group than those in the control group $(92.9 \mathrm{mg} / \mathrm{dL}$ vs. $93.4 \mathrm{mg} / \mathrm{dL}, P=0.004)$. The mean duration of ATD treatment was $3.8 \pm 0.8$ years.

Among the 4,593 patients with long-standing Graves' disease, 4,491 (97.8\%) were in the ATD group and 102 (2.2\%) were in the RIA group (Supplemental Table S1). The patients in the ATD group were older than those in the RIA group (median 48 years vs. 40.1 years, $P<0.001$ ) and had a higher proportion of female patients $(65.3 \%$ vs. $50.0 \%, P=0.001)$. Metabolic parameters were similar between the two groups except for BMI, which was significantly higher in the RIA group than in the ATD group $\left(24 \mathrm{~kg} / \mathrm{m}^{2}\right.$ vs. $\left.23.3 \mathrm{~kg} / \mathrm{m}^{2}, P=0.025\right)$. The mean duration of ATD treatment was $3.7 \pm 0.8$ years in ATD group and $4.7 \pm 2.2$ years in RIA group $(P<0.001)$.

\section{Risk of new-onset diabetes}

During the mean follow-up duration of 7.3 years, DM was diagnosed in 751 (16.3\%) patients with long-standing Graves' disease and 6,424 (14.0\%) subjects in the control group. Fig. 2A shows the cumulative incidence of DM, with a significant difference observed between the two groups (log-rank $P<0.001)$.
With the control group as reference, the HR for DM was 1.18 ( $95 \%$ CI, 1.1 to $1.28 ; P<0.001$ ) in patients with hyperthyroidism after complete adjustment by Model 3 (Table 2).

Further analyses were performed for groups based on the treatment modalities. As shown in Fig. 2B, the cumulative incidence of DM differed significantly among the three groups (logrank $P<0.001)$. The HR for DM was 1.17 (95\% CI, 1.08 to $1.27 ; P<0.001)$ in the ATD group and $1.88(95 \% \mathrm{CI}, 1.22$ to $2.88 ; P=0.004)$ in the RIA group after complete adjustment (Table 3). Notably, with the ATD group as a reference, the RIA group had an increased risk of DM with HR 1.56 (95\% CI, 1.01 to $2.42 ; P=0.045)$. When stratified according to the duration of ATD treatment (2-3, 3-4, and $\geq 4$ years), the risk of diabetes increased with the increase in duration of the ATD treatment $(P$ for trend $=0.019$ ).

\section{Subgroup analyses}

Subgroup analyses were performed based on the subgroups stratified by age ( $<55$ years vs. $\geq 55$ years), sex, BMI $\left(<25 \mathrm{~kg} / \mathrm{m}^{2}\right.$ vs. $\left.\geq 25 \mathrm{~kg} / \mathrm{m}^{2}\right)$, smoking status, heavy alcohol consumption, presence of hypertension, and presence of dyslipidemia and are plotted in Fig. 3. In comparison to the control group, the increased risk of DM in the hyperthyroidism group was more prominent in individuals with BMI $<25 \mathrm{~kg} / \mathrm{m}^{2}$ ( $P$ for interaction $=0.009)$ and those without underlying dyslipidemia ( $P$ for interaction $=0.004$ ). No effect modification was observed according to age, sex, smoking status, alcohol consumption, and presence of hypertension. 


\begin{tabular}{|c|c|c|c|}
\hline Characteristic & $\begin{array}{c}\text { Control } \\
(n=45,930)\end{array}$ & $\begin{array}{l}\text { Long-standing Graves' patients } \\
\qquad(n=4,593)\end{array}$ & $P$ value \\
\hline Age, yr & $48(40-56)$ & $48(40-56)$ & 0.056 \\
\hline Sex & & & 1.000 \\
\hline Male & $16,070(35.0)$ & $1,607(35.0)$ & \\
\hline Female & $29,860(65.0)$ & $2,986(65.0)$ & \\
\hline Smoking & & & $<0.001$ \\
\hline Never smoker & $33,312(72.5)$ & $3,114(67.8)$ & \\
\hline Ex-smoker & $4,430(9.6)$ & $590(12.8)$ & \\
\hline Current smoker & $8,188(17.8)$ & $889(19.4)$ & \\
\hline Heavy alcohol consumption & $2,524(5.5)$ & $128(2.8)$ & $<0.001$ \\
\hline Regular exercise & $10,695(23.3)$ & $1,080(23.5)$ & 0.727 \\
\hline Body mass index, $\mathrm{kg} / \mathrm{m}^{2}$ & $23.4 \pm 3.2$ & $23.3 \pm 3.1$ & 0.098 \\
\hline Systolic BP, mm Hg & $120.0 \pm 15.0$ & $121.1 \pm 14.6$ & $<0.001$ \\
\hline Diastolic BP, mm Hg & $75.0 \pm 10.1$ & $75.0 \pm 9.5$ & 0.883 \\
\hline Total cholesterol, mg/dL & $196.4 \pm 36.6$ & $190.6 \pm 35.8$ & $<0.001$ \\
\hline $\mathrm{HDL}-\mathrm{C}, \mathrm{mg} / \mathrm{dL}$ & $57.1 \pm 18.9$ & $57.5 \pm 13.6$ & 0.129 \\
\hline LDL-C, mg/dL & $116.0 \pm 39.0$ & $111.4 \pm 35.5$ & $<0.001$ \\
\hline Fasting glucose, mg/dL & $93.4 \pm 14.1$ & $92.9 \pm 12.4$ & 0.004 \\
\hline \multicolumn{4}{|l|}{ Comorbidities } \\
\hline Hypertension & $2,526(5.5)$ & $257(5.6)$ & 0.786 \\
\hline Dyslipidemia & $4,907(10.7)$ & $647(14.1)$ & $<0.001$ \\
\hline Duration of antithyroid drug treatment, yr & - & $3.8 \pm 0.8$ & - \\
\hline RIA $^{\mathrm{a}}$ & & $102(2.2)$ & - \\
\hline Antithyroid drugs $\mathrm{s}^{\mathrm{b}}$ & & & - \\
\hline Methimazole & - & $3,240(70.5)$ & \\
\hline Carbimazole & - & $544(11.8)$ & \\
\hline PTU & - & $3,280(71.4)$ & \\
\hline \multicolumn{4}{|c|}{$\begin{array}{l}\text { Values are expressed as median (interquartile range), number }(\%) \text {, or mean } \pm \text { standard deviation. } \\
\text { BP, blood pressure; HDL-C, high-density lipoprotein cholesterol; LDL-C, low-density lipoprotein cholesterol; RIA, radioactive iodine ablation; PTU, } \\
\text { propylthiouracil. } \\
\text { a Subsequent RIA after the initial 24-month course of antithyroid drug treatment; }{ }^{b} \text { The frequency of drug use was calculated in duplicate when more than } \\
\text { one type of drug was used for one patient. }\end{array}$} \\
\hline
\end{tabular}

\section{DISCUSSION}

This nationwide cohort study evaluated the risk of DM in patients with long-standing Graves' disease following an initial 24-month course of ATD therapy. Findings from this study showed that patients had 1.18 times higher risk of developing DM than age- and sex-matched controls did, independent of known risk factors for DM. Notably, a difference in the risk of DM was observed according to subsequent treatment modalities. While patients continuing ATD treatment had 1.17 times
DM risk, those who underwent RIA had 1.88 times higher risk of DM than controls did. Furthermore, the risk of diabetes increased with the increase in the ATD treatment duration. To the best of our knowledge, this longitudinal study is the first to assess the incidence of diabetes in a unique dataset of patients with Graves' disease treated with ATDs for 24 months. Given that patients with long-standing Graves' disease were clearly more prone to diabetes than the general population, special attention needs to be given during follow-up to check for the development of DM in these patients, particularly those exposed 


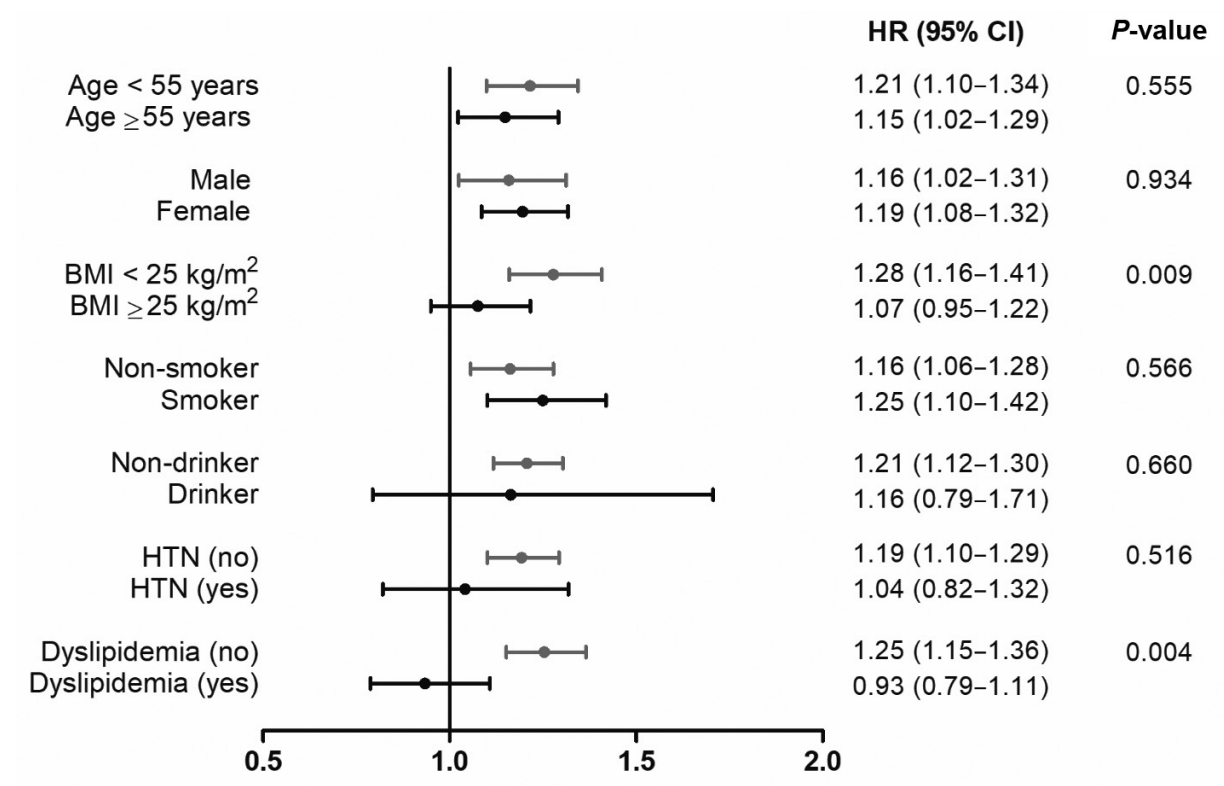

Fig. 3. Subgroup analysis comparing the hazard ratios (HRs) for developing diabetes between long-lasting graves' patients and matched control group. The HRs were determined by conducting a multivariate Cox proportional hazards regression analysis adjusting for age, sex, body mass index, smoking status, alcohol consumption, regular exercise, hypertension (HTN), dyslipidemia, systolic blood pressure, lowdensity lipoprotein, and fasting glucose. BMI, body mass index; CI, confidence interval.

Table 2. Hazard Ratios and 95\% Confidence Intervals for Diabetes Incidence

\begin{tabular}{lcc}
\hline & $\begin{array}{c}\text { Control group } \\
(n=45,930)\end{array}$ & $\begin{array}{c}\text { Treatment group } \\
(n=4,593)\end{array}$ \\
\hline Unadjusted & 1 (reference) & $1.17(1.09-1.27)$ \\
Model 1 & 1 (reference) & $1.17(1.09-1.26)$ \\
Model 2 & 1 (reference) & $1.15(1.07-1.24)$ \\
Model 3 & 1 (reference) & $1.18(1.10-1.25)$
\end{tabular}

Model 1: age, sex, body mass index (BMI); Model 2: age, sex, BMI, smoking status, alcohol consumption, regular exercise, hypertension, and dyslipidemia; Model 3: age, sex, BMI, smoking status, alcohol consumption, regular exercise, hypertension, dyslipidemia, systolic blood pressure, low-density lipoprotein, and fasting glucose.

to prolonged hyperthyroidism.

Recognition of the association between hyperthyroidism and DM dates back to 1927, when Coller and Huggins [24] presented a case series of 12 patients with coexisting hyperthyroidism and DM. They observed that hyperglycemia worsened owing to hyperthyroidism in these patients, and dramatic improvement in glycemic control was achieved after thyroidectomy. Hereafter, the deleterious effects of excessive thyroid hormone on glucose metabolism have been widely investigated and are now considered evident [25-28]. However, the risk of developing new-onset DM in patients with hyperthyroidism in clinical practice re-
Table 3. Hazard Ratios and 95\% Confidence Intervals for Diabetes According to Treatment Modality

\begin{tabular}{cccc}
\hline & $\begin{array}{c}\text { Control group } \\
(n=45,930)\end{array}$ & $\begin{array}{c}\text { ATD group } \\
(n=4,491)\end{array}$ & $\begin{array}{c}\text { RIA group } \\
(n=102)\end{array}$ \\
\hline Unadjusted & 1 (reference) & $1.17(1.08-1.26)$ & $1.56(1.01-2.38)$ \\
Model 1 & 1 (reference) & $1.16(1.07-1.25)$ & $1.83(1.19-2.81)$ \\
Model 2 & 1 (reference) & $1.15(1.05-1.23)$ & $1.79(1.17-2.75)$ \\
Model 3 & 1 (reference) & $1.17(1.08-1.27)$ & $1.88(1.22-2.88)$ \\
Unadjusted & - & 1 (reference) & $1.33(0.86-2.05)$ \\
Model 1 & - & 1 (reference) & $1.55(1.10-2.39)$ \\
Model 2 & - & 1 (reference) & $1.54(0.99-2.38)$ \\
Model 3 & - & 1 (reference) & $1.56(1.01-2.42)$ \\
\hline
\end{tabular}

Model 1: age, sex, body mass index (BMI); Model 2: age, sex, BMI, smoking status, alcohol consumption, regular exercise, hypertension, and dyslipidemia; Model 3: age, sex, BMI, smoking status, alcohol consumption, regular exercise, hypertension, dyslipidemia, systolic blood pressure, low-density lipoprotein, and fasting glucose.

ATD, antithyroid drug; RIA, radioactive iodine ablation.

mains elusive, and current guidelines for the management of hyperthyroidism do not mention practices for monitoring serum glucose levels or screening for diabetes in patients with hyperthyroidism [29-31]. Moreover, only a few longitudinal studies have assessed the risk of DM in patients with thyroid dysfunction [32-35], with the majority reporting an association with hy- 
pothyroidism. Only one study was relevant to hyperthyroidism and reported an HR of 1.46 (95\% CI, 1.16 to 1.84) for DM diagnosis after hyperthyroidism onset [32]. However, this study was a registry-based study that lacked information on baseline metabolic parameters and type of treatment that the patients received. In addition, the HR of the cited study was only adjusted for the degree of comorbidity preceding the diagnosis of hyperthyroidism using the Charlson score. Lastly, the risk of DM was not compared based on the treatment methods for hyperthyroidism. Meanwhile, our study adjusted for various confounding factors related to DM and observed that patients with longstanding Graves' disease pose a higher risk of DM with an HR of 1.18. Given the high prevalence of diabetes in the general population, the implication of this additional $18 \%$ absolute risk could be very significant and may raise the necessity for glucose testing of hyperthyroid patients. Interestingly, in our subgroup analyses, the risk of diabetes was particularly prominent in patients with relatively low BMI and those without dyslipidemia. Traditionally, high BMI and the presence of dyslipidemia are regarded as major risk factors for DM [36-38]. Thus, our findings that patients without these risk factors are at a higher risk of diabetes imply that the detrimental effect of hyperthyroidism may be more pronounced in patients in the absence of conventional risk factors and should be monitored more carefully.

Notably, in the present study, patients who underwent RIA had 1.6 times higher risk of DM than patients treated with ATD alone. Though the exact reason for this observation is unclear, it may partially be explained by the difference in disease severity between the two groups; patients in the RIA group in our study could have had a more severe degree of hyperthyroidism. In Korea, the use of RIA is very limited, even in cases with recurrence of hyperthyroidism after ATD treatment [39], as observed in our study cohort in which only $2.2 \%$ of patients with longstanding Graves' disease underwent RIA. Clinicians in Korea tend to maintain ATD treatment for years $[40,41]$; therefore, patients in the RIA group in our study may represent those who had highly uncontrolled or severe hyperthyroidism that could not be managed with ATDs alone. In fact, the duration of ATD treatment was longer for patients who underwent RIA than for those who continued ATD treatment (4.7 years vs. 3.7 years). Eventually, patients in the RIA group were at a significantly higher risk of diabetes, and taken together, it may be inferred that those with uncontrolled hyperthyroidism are at an increased risk of diabetes. This is supported by the fact that the longer the ATD treatment, the higher the risk of DM as observed in our study. We can readily assume that patients who required to be treated with ATD for a longer duration are those with persistent and/or uncontrolled Graves' disease. However, as thyroid function test (TFT) data were not available in our dataset, we could not validate whether the difference in the risk of DM according to treatment methods resulted from the difference in disease severity. Meanwhile, RIA itself may have a negative effect on glycemic control. For instance, a few studies have reported the development of hyperglycemia after RIA for hyperthyroidism $[42,43]$. The pancreas expresses the sodium-iodine symporter (NIS) [44] and can take up radioactive iodine via NIS, which may lead to damage in pancreatic beta-cells by producing reactive oxygen species $[45,46]$ or directly damaging the DNA $[46,47]$. Though further studies are needed to clarify the reason why the RIA group had a higher risk of DM than the ATD group, our results suggest that the effective control of hyperthyroidism is paramount in reducing the risk of diabetes.

Several mechanisms have been identified regarding the effects of thyroid hormones on glucose metabolism. Excess thyroid hormones promote hyperglycemia mainly by increasing hepatic glucose output [12]. Thyroid hormones elevate the concentrations of glucose transporter 2 , the main glucose transporter in the liver, particularly in the hepatocyte plasma membrane, which leads to increased hepatic glucose output [48,49]. Excess thyroid hormone also enhances catecholamine-induced lipolysis, and a subsequent increase in free fatty acids stimulates hepatic gluconeogenesis [50]. Furthermore, a reduction in the halflife of insulin due to enhanced degradation and an increased release of biologically inactive insulin precursors [51,52] also induces hyperglycemia. Another mechanism for hyperthyroidismmediated hyperglycemia may be owing to the increase in gut absorption of glucose $[53,54]$. These observations provide a robust basis for the results from our study that patients with longstanding Graves' disease are at a higher risk for DM than those without hyperthyroidism. In the long-term, coexistence of hyperthyroidism and DM can mutually exacerbate the risk of cardiovascular risk in each condition [55], which highlights the need for the early detection of dysglycemic states in hyperthyroidism patients.

This study has some limitations. First, this study was designed retrospectively; thus, selection bias and clinicians' preference for choosing treatment modality could not be completely eliminated. Second, there is a lack of information on TFTs. This limited the evaluation of the severity of hyperthyroidism at diagnosis and the comparison between the groups. Third, the diagnosis was based on ICD-10 codes, and an accurate diagnosis of Graves' disease was unavailable. However, Graves' disease ac- 
counts for the majority (82.7\%) of hyperthyroidism cases in Korea, with toxic adenoma accounting for less than $1 \%$ [39]; thus, it can be inferred that patients using ATD for $\geq 24$ months would most likely be those with Graves' disease. Despite these limitations, the strength of this study lies in its longitudinal design using a large sample size cohort to assess the risk of diabetes in patients initially treated with ATDs for 24 months, representing the real-world clinical setting where ATD is globally used as primary treatment in more than half of Graves' disease cases [3,39].

In conclusion, patients with long-standing Graves' disease have a significantly higher risk of DM than the general population, and the risk increases with increased treatment duration of Graves' disease. A systematic approach to glucose monitoring in patients with Graves' disease during follow-up, along with effective control of hyperthyroidism, may be reasonable to reduce the risk of developing DM in these patients.

\section{CONFLICTS OF INTEREST}

No potential conflict of interest relevant to this article was reported.

\section{ACKNOWLEDGMENTS}

This work was supported by the Korea Health Technology R\&D Project through the Korea Health Industry Development Institute (KHIDI), funded by the Ministry of Health \& Welfare, Republic of Korea (grant number HR20C0021), the National Research Foundation of Korea funded by the Ministry of Education of Korea (2021R1A2C2008792), and the Korea Medical Device Development Fund grant funded by the Korea government (the Ministry of Science and ICT, the Ministry of Trade, Industry and Energy, the Ministry of Health \& Welfare, the Ministry of Food and Drug Safety) (Project Number: 9991007469, KMDF_PR_20200901_0233). Moreover, this study used National Health Insurance Service data (NHIS-20201-098). The authors would like to thank all the staff of the National Health Insurance Sharing Service.

\section{AUTHOR CONTRIBUTIONS}

Conception or design: E.S., H.J.Y. Acquisition, analysis, or interpretation of data: E.S., M.J.K., E.N., S.Y.H., M.J.P., J.A.K., E.R. Drafting the work or revising: E.S., K.M.C., S.H.B., G. J.C., H.J.Y. Final approval of the manuscript: E.S., H.J.Y.

\section{ORCID}

Eyun Song https://orcid.org/0000-0002-6034-0758

Hye Jin Yoo https://orcid.org/0000-0003-0600-0266

\section{REFERENCES}

1. De Leo S, Lee SY, Braverman LE. Hyperthyroidism. Lancet 2016;388:906-918.

2. Cooper DS. Hyperthyroidism. Lancet 2003;362:459-68.

3. Burch HB, Burman KD, Cooper DS. A 2011 survey of clinical practice patterns in the management of Graves' disease. J Clin Endocrinol Metab 2012;97:4549-58.

4. Brito JP, Schilz S, Singh Ospina N, Rodriguez-Gutierrez R, Maraka S, Sangaralingham LR, et al. Antithyroid drugs-the most common treatment for Graves' disease in the United States: a nationwide population-based study. Thyroid 2016; 26:1144-5.

5. Abraham P, Avenell A, McGeoch SC, Clark LF, Bevan JS. Antithyroid drug regimen for treating Graves' hyperthyroidism. Cochrane Database Syst Rev 2010;2010:CD003420.

6. Azizi F, Amouzegar A, Tohidi M, Hedayati M, Khalili D, Cheraghi $\mathrm{L}$, et al. Increased remission rates after long-term methimazole therapy in patients with Graves' disease: results of a randomized clinical trial. Thyroid 2019;29:1192-200.

7. Chung JH. Antithyroid drug treatment in Graves' disease. Endocrinol Metab (Seoul) 2021;36:491-9.

8. Rajput R, Jain D, Pathak V, Dangi A. Diabetic ketoacidosis and thyroid storm: coexistence of a double trouble. BMJ Case Rep 2018;2018:bcr2018225748.

9. Perros P, McCrimmon RJ, Shaw G, Frier BM. Frequency of thyroid dysfunction in diabetic patients: value of annual screening. Diabet Med 1995;12:622-7.

10. Kadiyala R, Peter R, Okosieme OE. Thyroid dysfunction in patients with diabetes: clinical implications and screening strategies. Int J Clin Pract 2010;64:1130-9.

11. Wu P. Thyroid disorders and diabetes: it is common for a person to be affected by both thyroid disease and diabetes. Diabetes Self Manag 2007;24:80-2,85-7.

12. Brenta G, Danzi S, Klein I. Potential therapeutic applications of thyroid hormone analogs. Nat Clin Pract Endocrinol Metab 2007;3:632-40.

13. Goglia F, Moreno M, Lanni A. Action of thyroid hormones at the cellular level: the mitochondrial target. FEBS Lett 1999;452:115-20.

14. Wang C. The relationship between type 2 diabetes mellitus 
and related thyroid diseases. J Diabetes Res 2013;2013: 390534.

15. Crunkhorn S, Patti ME. Links between thyroid hormone action, oxidative metabolism, and diabetes risk? Thyroid 2008; 18:227-37.

16. Gray RS, Irvine WJ, Clarke BF. Screening for thyroid dysfunction in diabetics. Br Med J 1979;2:1439.

17. Mouradian M, Abourizk N. Diabetes mellitus and thyroid disease. Diabetes Care 1983;6:512-20.

18. Nerup J, Binder C. Thyroid, gastric and adrenal auto-immunity in diabetes mellitus. Acta Endocrinol (Copenh) 1973;72: 279-86.

19. Radetti G, Paganini C, Gentili L, Bernasconi S, Betterle C, Borkenstein M, et al. Frequency of Hashimoto's thyroiditis in children with type 1 diabetes mellitus. Acta Diabetol 1995; 32:121-4.

20. Fleiner HF, Bjoro T, Midthjell K, Grill V, Asvold BO. Prevalence of thyroid dysfunction in autoimmune and type 2 diabetes: the population-based HUNT study in Norway. J Clin Endocrinol Metab 2016;101:669-77.

21. Ogbonna SU, Ezeani IU. Risk factors of thyroid dysfunction in patients with type 2 diabetes mellitus. Front Endocrinol (Lausanne) 2019;10:440.

22. Lee J, Lee JS, Park SH, Shin SA, Kim K. Cohort profile: the National Health Insurance Service-National Sample Cohort (NHIS-NSC), South Korea. Int J Epidemiol 2017;46:e15.

23. Allannic H, Fauchet R, Orgiazzi J, Madec AM, Genetet B, Lorcy $\mathrm{Y}$, et al. Antithyroid drugs and Graves' disease: a prospective randomized evaluation of the efficacy of treatment duration. J Clin Endocrinol Metab 1990;70:675-9.

24. Coller FA, Huggins CB. Effect of hyperthyroidism upon diabetes mellitus: striking improvement in diabetes mellitus from thyroidectomy. Ann Surg 1927;86:877-84.

25. Elrick H, Hlad CJ Jr, Arai Y. Influence of thyroid function on carbohydrate metabolism and a new method for assessing response to insulin. J Clin Endocrinol Metab 1961;21:387400.

26. Hales CN, Hyams DE. Plasma concentrations of glucose, non-esterified fatty acid, and insulin during oral glucose-tolerance tests in thyrotoxicosis. Lancet 1964;2:69-71.

27. Kreines K, Jett M, Knowles HC Jr. Observations in hyperthyroidism of abnormal glucose tolerance and other traits related to diabetes mellitus. Diabetes 1965;14:740-4.

28. Doar JW, Stamp TC, Wynn V, Audhya TK. Effects of oral and intravenous glucose loading in thyrotoxicosis: studies of plasma glucose, free fatty acid, plasma insulin and blood pyruvate levels. Diabetes 1969;18:633-9.

29. Kahaly GJ, Bartalena L, Hegedus L, Leenhardt L, Poppe K, Pearce SH. 2018 European Thyroid Association guideline for the management of Graves' hyperthyroidism. Eur Thyroid J 2018;7:167-86.

30. Ross DS, Burch HB, Cooper DS, Greenlee MC, Laurberg P, Maia AL, et al. 2016 American Thyroid Association guidelines for diagnosis and management of hyperthyroidism and other causes of thyrotoxicosis. Thyroid 2016;26:1343-421.

31. Moon JH, Yi KH. The diagnosis and management of hyperthyroidism in Korea: consensus report of the Korean Thyroid Association. Endocrinol Metab (Seoul) 2013;28:275-9.

32. Brandt F, Thvilum M, Almind D, Christensen K, Green A, Hegedus L, et al. Morbidity before and after the diagnosis of hyperthyroidism: a nationwide register-based study. PLoS One 2013;8:e66711.

33. Gronich N, Deftereos SN, Lavi I, Persidis AS, Abernethy DR, Rennert G. Hypothyroidism is a risk factor for new-onset diabetes: a cohort study. Diabetes Care 2015;38:1657-64.

34. Thvilum M, Brandt F, Almind D, Christensen K, Brix TH, Hegedus L. Type and extent of somatic morbidity before and after the diagnosis of hypothyroidism: a nationwide register study. PLoS One 2013;8:e75789.

35. Chaker L, Ligthart S, Korevaar TI, Hofman A, Franco OH, Peeters RP, et al. Thyroid function and risk of type 2 diabetes: a population-based prospective cohort study. BMC Med 2016;14:150.

36. Ganz ML, Wintfeld N, Li Q, Alas V, Langer J, Hammer M. The association of body mass index with the risk of type 2 diabetes: a case-control study nested in an electronic health records system in the United States. Diabetol Metab Syndr 2014;6:50.

37. Mooradian AD. Dyslipidemia in type 2 diabetes mellitus. Nat Clin Pract Endocrinol Metab 2009;5:150-9.

38. Johansen Taber KA, Dickinson BD. Genomic-based tools for the risk assessment, management, and prevention of type 2 diabetes. Appl Clin Genet 2015;8:1-8.

39. Yi KH, Moon JH, Kim IJ, Bom HS, Lee J, Chung WY, et al. The diagnosis and management of hyperthyroidism consensus: report of the Korean Thyroid Association. J Korean Thyroid Assoc 2013;6:1-11.

40. Kim YA, Cho SW, Choi HS, Moon S, Moon JH, Kim KW, et al. The second antithyroid drug treatment is effective in relapsed Graves' disease patients: a median 11-year followup study. Thyroid 2017;27:491-6.

41. Park SY, Kim BH, Kim M, Hong AR, Park J, Park H, et al. 
The longer the antithyroid drug is used, the lower the relapse rate in Graves' disease: a retrospective multicenter cohort study in Korea. Endocrine 2021;74:120-7.

42. Hu Y, Gao G, Yan RN, Li FF, Su XF, Ma JH. Glucose metabolism before and after radioiodine therapy of a patient with Graves' disease: assessment by continuous glucose monitoring. Biomed Rep 2017;7:183-7.

43. Kiani J, Yusefi V, Tohidi M, Mehrabi Y, Azizi F. Evaluation of glucose tolerance in methimazole and radioiodine treated Graves' patients. Int J Endocrinol Metab 2010;8:132-7.

44. Spitzweg C, Joba W, Schriever K, Goellner JR, Morris JC, Heufelder AE. Analysis of human sodium iodide symporter immunoreactivity in human exocrine glands. J Clin Endocrinol Metab 1999;84:4178-84.

45. Riley PA. Free radicals in biology: oxidative stress and the effects of ionizing radiation. Int J Radiat Biol 1994;65:27-33.

46. Samadi R, Shafiei B, Azizi F, Ghasemi A. Radioactive iodine therapy and glucose tolerance. Cell J 2017;19:184-93.

47. Sundaram PS, Padma S, Sudha S, Sasikala K. Transient cytotoxicity of ${ }^{131} \mathrm{I}$ beta radiation in hyperthyroid patients treated with radioactive iodine. Indian J Med Res 2011;133:401-6.

48. Kemp HF, Hundal HS, Taylor PM. Glucose transport corre- lates with GLUT2 abundance in rat liver during altered thyroid status. Mol Cell Endocrinol 1997;128:97-102.

49. Mokuno T, Uchimura K, Hayashi R, Hayakawa N, Makino M, Nagata M, et al. Glucose transporter 2 concentrations in hyper- and hypothyroid rat livers. J Endocrinol 1999;160:285-9.

50. Vaughan M. An in vitro effect of triiodothyronine on rat adipose tissue. J Clin Invest 1967;46:1482-91.

51. Dimitriadis G, Baker B, Marsh H, Mandarino L, Rizza R, Bergman R, et al. Effect of thyroid hormone excess on action, secretion, and metabolism of insulin in humans. Am J Physiol 1985;248(5 Pt 1):E593-601.

52. O'Meara NM, Blackman JD, Sturis J, Polonsky KS. Alterations in the kinetics of C-peptide and insulin secretion in hyperthyroidism. J Clin Endocrinol Metab 1993;76:79-84.

53. Levin RJ, Smyth DH. The effect of the thyroid gland on intestinal absorption of hexoses. J Physiol 1963;169:755-69.

54. Matty AJ, Seshadri B. Effect of thyroxine on the isolated rat intestine. Gut 1965;6:200-2.

55. Sarfo-Kantanka O, Sarfo FS, Ansah EO, Kyei I. The effect of thyroid dysfunction on the cardiovascular risk of type 2 diabetes mellitus patients in Ghana. J Diabetes Res 2018;2018: 4783093. 